\title{
Evaluating Lean Thinking and Facility Design in Two University Hospitals
}

\author{
Virpi Ruohomäki ${ }^{1}$, Emmi Reijula ${ }^{2}$, Jori Reijula ${ }^{3, *}$ \\ ${ }^{1}$ Finnish Institute of Occupational Health, Finland \\ ${ }^{2}$ Kuopio University Hospital, Finland \\ ${ }^{3}$ Granlund Consulting, Finland
}

Copyright $(2017$ by authors, all rights reserved. Authors agree that this article remains permanently open access under the terms of the Creative Commons Attribution License 4.0 International License

\begin{abstract}
Hospitals will be expected to work more efficiently in the upcoming years due to several factors, one of which is aging population groups. Meanwhile, healthcare resources are dwindling, as is the amount of available personnel. This paper examines interviews and questionnaires that were conducted to assess the experiences and effects of Lean implementation in two university hospitals. Several factors, such as emphasis on the participatory, user-centric design approach and integrating Lean as an integral part of the operational facility design process in both target hospitals have proven to be beneficial. This study delivers promising evidence from the two university hospitals, which supports the implementation of Lean in the healthcare sector for improving facility design and work processes.
\end{abstract}

Keywords Healthcare, Hospitals, Lean, Questionnaires, Interviews, Facility Design, Work Processes

\section{Introduction}

The healthcare processes and work environment design in developed countries today are in dire need of improvement and under great pressure (due to e.g. population aging) to develop [1, 2]. Far too often, healthcare facilities are outdated, inadaptable, or otherwise inadequate for promoting efficient healthcare processes [3]. However, merely building new or renovating existing healthcare facilities is not enough: They must be insightfully designed and developed in terms of operational efficiency to ensure that they support flowing, streamlined healthcare processes [4-6]. Time is running out, and ever-dwindling healthcare resources are becoming scarcer [7]. Even the most old-fashioned hospital management and facility designers must take heed - new initiatives must be carried out as soon as possible.

A solid fundamental framework is essential for successful facility design. A relatively well-known innovation, Lean thinking, has shown great potential for eliminating waste from work processes and improving healthcare efficiency in hospitals [8, 9]. Lean has made a visible impact in several industry sectors during the past decade, and has been increasingly utilized in healthcare facility design [10]. The results of its implementation in Scandinavian hospitals have varied, and questions have arisen as to whether standardized Lean work processes are too repetitive, and whether they limit variation within individual work tasks and employees' opportunities to design their own work $[11,12]$. This could make work physically and mentally straining, and work ergonomics repetitive and deteriorating. To quell these doubts, a vast collection of positive results attained by Lean implementation projects - improved work processes, staff and customer satisfaction, decreased inventory and treatment costs and improved productivity in HC organizations - has strengthened the notion of Lean [13-16]. Information on the basics of Lean can be found in, for example, Liker and Meier [17].

Eager to develop, Finnish university hospitals have been actively attempting to apply Lean tools and methods in their healthcare work processes and facility design. This study focuses on the implementation endeavors of two Finnish university hospitals on their path to learning the fundamentals of Lean philosophy and implementing Lean methods and tools. The first aim is to assess and learn from trials and errors in healthcare facility design processes from the perspective of the hospital facility designers and managers involved in the process. Another aim is to assess the implementation and effects of Lean and facility design from the perspective of the employees. In this study, the employees relocated from an old hospital facility to a new one, and evaluated its functionality. This paper illustrates the key findings of the Lean design projects from the perspectives of the designers, managers and employees, and reveals the issues that arose during the operational facility design phase. 


\section{Materials and Methods}

\subsection{Hospital Districts}

The study targets, two university hospitals ( $\mathrm{H} 1$ and $\mathrm{H} 2)$, cover one fifth of the entire area of Finnish university hospitals. The population covered by each broadly spans one million Finnish citizens. Both $\mathrm{H} 1$ and $\mathrm{H} 2$ comprise all major clinical expertise, and have recently implemented Lean.

\subsection{Interview Study}

In 2015, we carried out semi-structured interviews of facility managers, designers and other stakeholders $(n=14)$ with major roles in the facility design projects conducted in $\mathrm{H} 1$ or $\mathrm{H} 2$. The interviews were audio recorded, and each lasted approximately one hour. Half of the interviewees ( $\mathrm{n}=$ 7) had participated in renovation projects in $\mathrm{H} 1$, and the rest were involved in $\mathrm{H} 2$ renovation projects.

We analyzed the data using the inductive content analysis method with ATLAS.ti 7.1. 3 software (Graneheim \& Lundman, 2004). First, we read the data numerous times in order to gain an overview. The meaning units were extracted and then thematically connected and coded. Next, we grouped the coded phrases with similar contents and abstracted them into subcategories. Finally, we sorted the subcategories into main categories.

\subsection{Questionnaire study}

Questionnaires were sent to $350 \mathrm{H} 1 \mathrm{employees}$ relocating from an old hospital building to a newly built one. The study was conducted using longitudinal data, involving two assessments via a questionnaire: first in the old H1 hospital before relocation in 2015, and second in the new hospital after relocation in 2016. The second questionnaire served as a post-occupancy evaluation nearly a year after occupation of the facility [18].

The number of respondents was 103 (response rate 32\%) in 2015, and 119 (response rate 34\%) in 2016. They represented nurses, physiotherapists, medical doctors, and other professionals; were mainly female $(81 \%)$, and had an average of 20 years of work experience in the field of health care.

The questionnaire measured the following variables: the utilization of Lean in H1, the quality and functionality of the work environment, work performance, and work engagement. We also used research data that assessed the target hospitals' use of Lean.

The data were analyzed with descriptive statistics using the SAS for Windows statistical software package. The statistical differences between the variables of the questionnaires in 2015 and 2016 were analyzed using the Chi-square test. We investigated whether the distributions of categorical variables differed from one another. The critical level of significance was set to 0.05 in the statistical analyses.
Here we report only the results that were statistically different.

\section{Results}

\subsection{Interview Results}

The integration of Lean as the main part of the operational facility design process proved beneficial in $\mathrm{H} 1$ and $\mathrm{H} 2$. In addition, positive results were observed in the thorough orientation of clinicians in the newly designed work environments and processes. Lean tools, such as value stream mapping and patient flow charts had been utilized in operational facility design and work process planning. Moreover, Lean tools 5S, Kanban signals and the A3 problem solving tool were commonly utilized in both hospitals. The success of Lean implementation had led to increased initiatives to implement Lean more systematically in everyday work processes in both target hospitals.

According to the interview study results, $\mathrm{H} 1$ and $\mathrm{H} 2$ facility design had succeeded in fulfilling the desirable design criteria for indoor environment design, heating, ventilation and air-conditioning (HVAC), ergonomics, accessibility, and safety. The interviews also revealed that the participatory, user-centric design approach had improved several aspects of facility design, such as staff satisfaction and trust. What is more, the hospital units that had systematically involved their users in the decision-making process had won their commitment and encountered little resistance from them during and after facility design projects.

The interviewees saw the target hospitals as highly bureaucratic organizations with a tendency to slowly implement changes, such as new innovations or security upgrades/updates. Some issues were observed in teamwork concerning $\mathrm{H} 1$ and $\mathrm{H} 2$ facility design projects, but these could have been solved by clarifying the reasons behind the project's decision-making process. Logistics and navigation challenges were also apparent in both hospitals. Accurate scheduling, setting timeframes, and cost-estimate calculation seemed to present difficulties for facility design project personnel. The interviewees pointed out that outsourced contractors were occasionally assigned with obscure criteria.

The interviewees felt that architects and designers should be able to interact with clinicians and should have sufficient healthcare expertize. Facility design projects should be led systematically, using a goal-oriented approach. Project communication should be transparent and led by a facilitator - preferably from within the hospital. Furthermore, an organized healthcare facility design forum was seen as beneficial for sharing knowledge. Personnel knowledge of past projects was also considered a valuable asset and worth rigorous utilization.

The interviewees believed that the hospital had 
development needs associated with facility design project management, including guidance on project-based facility design, utilizing users' know-how, and getting everyone involved in the design process. They also felt that a more dynamic personnel structure was needed and that the silo mentality and its resulting hierarchy among the hospital personnel should be eliminated. Moreover, information and communication systems were partly outdated and in urgent need of reformation.

\subsection{Questionnaire Results}

The results showed an increase in the employees' awareness of Lean thinking and its utilization at their workplace. In $2015,53 \%$ of the respondents knew what Lean meant, whereas in 2016 this figure had risen to $77 \%$. In $2015,21 \%$ of the respondents believed that Lean was utilized at their workplace, whereas in 2016, this number was $51 \%$. Nevertheless, an increasing number of employees wished it could be taken more advantage of in the hospital work (40\% in 2015 and 50\% in 2016). Their suggestions for Lean utilization are presented in Table 1.

The results showed that the employees were more satisfied with the quality of their new work environment than the old one. Adjusting temperatures, ventilation and furniture had become easier. There were fewer perceived indoor air problems. Interior design quality had improved considerably. Employees were more satisfied with interior colors, tidiness and the safety of furniture and floor materials. They were also more satisfied with being able to see out of windows and customize their work environment.

The employees evaluated their new work premises as suitable and appropriate for carrying out work tasks and as supportive of individual tasks. They perceived that accessibility needs had been taken into account more, for example for people with allergies, or moving, hearing or seeing disabilities. The number of meeting rooms had increased, and finding a place to discuss confidential matters had become easier.

The results indicated that relocating to new facilities had resulted in greater satisfaction with work and work performance. The respondents also reported more often experiencing positive work engagement: feeling inspired and swept away by their work and becoming completely immersed in their work.

However, the employees perceived their new work environment as more unsettled than the old one. The new premises did not support interaction between individuals as well as before, and employees felt more isolated from their work community as it was more difficult to reach colleagues in the new environment. Moreover, cooperation among employees was assessed as less efficient after the relocation.

Table 1. Development ideas for Lean utilization

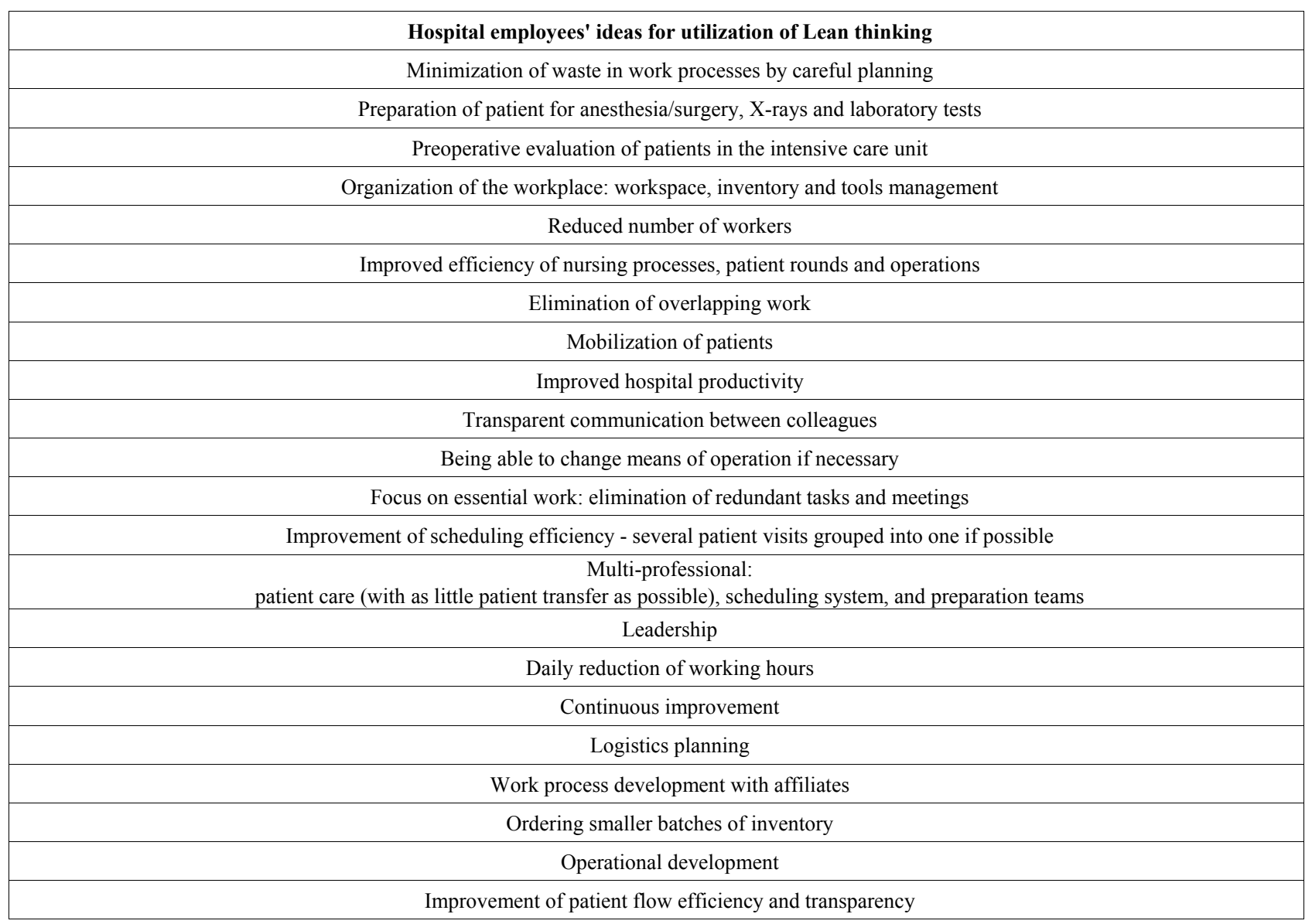




\section{Discussion}

Both the interviewees and questionnaire respondents seemed quite satisfied with the technical aspects of their work environments, such as HVAC, indoor air quality, ergonomics, accessibility, and the quality of interior design. The several key improvements reported by the questionnaire respondents positively affected their satisfaction and well-being. However, the decline in the crucial parameters concerning employees' cooperation, interaction and unsettledness were unexpected, and raise doubts as to whether the facility design had succeeded optimally from the employees' point of view. These results may be a natural side-effect of the still ongoing transition period. They may also reflect the challenges of radical workplace change processes and change management.

According to the interviews and questionnaires, the most salient issue in the target hospitals concerned the dynamics among the hospital personnel. Lean is a comprehensive framework that consists of a philosophy alongside a wide array of methods and tools for work processes and facility design. Due to this complexity, we considered it beneficial that the interviews cover not only the implementation of Lean but also more broadly the operational facility design and the encountered hardships in the $\mathrm{H} 1$ and $\mathrm{H} 2$ design projects. This enabled a thorough assessment of the implementation results of Lean in the hospitals' facility design processes.

When the interviews and questionnaires were first conducted in 2015, Lean was still a relatively new framework in both $\mathrm{H} 1$ and $\mathrm{H} 2$. Thus, even though several Lean tools and methods were utilized in the target hospitals, a significant proportion of the staff were unsure as to whether they were in fact "Lean", and what this actually meant. However, the number of employees aware of Lean had increased from 2015 to 2016, most likely due to visible initiatives carried out in the hospital.

The hospital employees' utilization ideas for Lean show that several employees had clearly grasped its meaning. Most of the suggestions were feasible and - with sufficient motivation and expertise - could be carried out using Lean tools and methods. Although rather abstract, the proposals addressed the most prominent improvement needs illustrated by the interviewees and questionnaire respondents. These included, for example, more efficient, transparent communication, systematic leadership, improvement of work processes, elimination of waste and redundant work tasks, logistics planning, inventory management, elimination of silos, and the creation of a more dynamic organization from an operational perspective.

Lean includes several tools and methods to fix these issues and fulfill the improvement needs reported by the interviewees and the questionnaire respondents in the target hospitals. First, by using value stream maps of current and future-state work processes, hospital work can be streamlined, waste eliminated, and work process bottlenecks located simultaneously [19]. A3 is an efficient tool for eliminating bottlenecks in daily work routines: Employees work in teams to locate the problem, find its root cause and fix the issue. By implementing A3 problem-solving as part of employees' everyday work routines, even the most difficult work process issues can be solved [20].

Hospital inventories are a hotspot of waste, and limiting this presents an opportunity to vastly improve hospital productivity. $5 \mathrm{~S}$ is an effective tool for hospital inventory management, and has also shown great results in organizing the work environment and eliminating waste [21]. Moreover, by utilizing Kanban signals to visualize the amount of inventory left and using reliable contractors for inventory refreshment, hospitals can minimize their inventories and pursue significant cost savings.

Systematic daily meetings and multi-professional problem-solving in care teams has shown to improve communication across hospital units/"silos" and to make issues transparent throughout the hospital [22]. Lean philosophy encourages hospital leaders to function as active, coach-like guides for the staff to help further enhance communication on concurrent topics, teamwork and staff cohesion. The results suggest that managers should take more active leadership in workplace change processes, and encourage employees' to take advantage of opportunities to participate. In the new work environment, employees also need support and thorough guidance from leaders. Otherwise, they are likely to resort to old ways of working, which may nullify the benefits of the new work environment [23].

The interviews and questionnaires revealed a need for developing leadership: Clear goals, systematic decision-making together with transparent, open communication between employees and the management were desired. Daily Gemba walks to inspect the hospital's everyday work have shown to help hospital leaders obtain a better perspective of the work processes, and to enable the leadership to make informed (preferably wiser) decisions concerning work process and facility design [10]. The management should pursue a culture of openness among individuals, and the best way to accomplish this is by leading through example. If the leadership clarifies its reasons for decision-making, for instance, grumbles and resistance by hospital staff may significantly decrease. Furthermore, the highest level of hospital management working alongside experienced Lean consultants is beneficial, especially in the earliest phases of a facility design project, since this reinforces the required knowledge and decision-making support needed by project management.

Although a need was expressed to comprehensively guide employees to project-based facility design process, involve employees, and utilize their practical work experience, the participatory approach had proven beneficial for both target hospitals. Empowering hospital employees to participate in the facility design process can highlight the user's point of view. Lean ideology suggests using standardized procedures such as multi-professional, specifically organized "Kaizen 
Blitz", Lean workshops, which systematically incorporate users' perspectives at various stages of the facility design process [24].

Moreover, although specialized, fixed positions and clear division of work in hospitals are common, this may not be beneficial to the hospital, since it may decrease the flexibility of the personnel structure to adjust to hospital process redesign. Lean hospitals aspire to become dynamic healthcare organizations by decreasing specialized positions and by training hospital staff to take care of a wider array of tasks and broader job contents. As the modern hospital patient increasingly has multiple sicknesses, which will likely require hospital readmissions, the need for cross-silo care and flexible staff is intensified [25].

Improving hospital work process efficiency can enhance hospital productivity. In some instances, this may enable a reduction in workload and thus also working hours for some heavily burdened employees. However, reducing staff because of hospital productivity improvements may not be morally/ethically acceptable, nor is it something Lean organizations aim to accomplish [10]. Furthermore, studies have shown that layoffs due to Lean improvements are detrimental to the organization, deteriorating for instance, trust, togetherness and teamwork among employees.

\section{Conclusions}

The Lean transformation in the target hospitals required a new mindset among hospital employees and the management. Although the journey towards Lean is still in its early stages, the initial responses - and results - have been mostly positive. The employees had gained a better grasp of the concept of Lean, and demonstrated an increased willingness to implement lean ideas in everyday work processes.

The prominent issues burdening the target hospitals included poor communication between employees; leadership and work process improvement needs; waste in, for example, certain hospital bottlenecks logistics and inventory management needs; dispersed hospital units/silos; and the need for a more dynamic organization. Although this list is long, the issues are common in today's hospitals. However, they can be overcome by systematically utilizing the tools and methods provided by Lean on a daily basis.

Perhaps the greatest challenge in implementing Lean lies in involving everyone in the new framework of daily work successfully. Lean requires a fresh new mindset, courage, strong willpower, and stamina: Continuous improvement does not take place without constant effort. Additional energy is initially required not only to perform the assigned work tasks, but to simultaneously devise ways in which to improve it. Furthermore, the ability to think "outside the box" about new solutions is novel for most healthcare practitioners. Stepping out of one's comfort zone will likely feel threatening at first, but is greatly rewarding when one sees the improvements in the work environment.

The old, rooted way of hierarchical silo thinking lies deep within most of today's healthcare organizations. Moreover, many still believe that what has worked before will suffice today. This is no longer true. Much like the growing evidence pointing towards the efficiency of dynamic, Lean healthcare organizations, this study found the effects of a Lean framework highly beneficial and worth adopting.

\section{Acknowledgements}

We are grateful to The Finnish Work Environment Fund and two University Hospitals for funding this research together with Finnish Institute of Occupational Health.

\section{REFERENCES}

[1] B. Kimball, E. O'Neill. Health Care's Human Crisis: The American Nursing Shortage, The Robert Wood Johnson Foundation, Princeton, NJ, Online available at: http://www.rwjf.org/content/dam/files/legacy-files/article-file s/2/NursingReport.pdf, 2002.

[2] U. Häkkinen, P. Martikainen, A. Noro, E. Nihtilä, M. Peltola. Aging, health expenditure, proximity to death, and income in Finland. Health Economics, Policy and Law, Vol.3, No.2, 165-195, 2008.

[3] J. Reijula, M. Gröhn, K. Müller, K. Reijula. Intelligent HVAC systems in hospitals, Intelligent Buildings International, Vol.5, No.2, 101-119, 2013.

[4] R. Ulrich, C. Zimring, X. Zhu, J. DuBose, H. Seo, Y. Coi, et al. A review of the research literature on evidence-based healthcare design, Health Environments Research and Design, Vol.1, No.3, 61-125, 2008.

[5] F. Becker, K. Parsons. Hospital facilities and the role of evidence-based design, Journal of Facilities Management, Vol.5, No.4, 263-274, 2007.

[6] J. Reijula, N. Nevala, M. Lahtinen, V. Ruohomäki, K. Reijula. Lean design improves both health-care facilities and processes: a literature review, Intelligent Buildings International, Vol.6, No.3, 170-185, 2014.

[7] S. Dai, C. Bancej, A. Bienek, P. Walsh, P. Stewart, A. Wielgosz. Tracking heart disease and stroke in Canada, Cronic Diseases in Canada, Vol.29, No.4, 192-193, 2009.

[8] N. Grunden, C. Hagood. Lean-Led Hospital Design, Cornwall, UK, CRC Press, 2012.

[9] J. Reijula, I. Tommelein. Lean hospitals: a new challenge for facility designers, Intelligent Buildings International, Vol.4, No.2, 126-143, 2012.

[10] M. Graban. Lean Hospitals - Improving Quality, Patient Safety and Employee Engagement, Boca Raton, FL, CRC Press, 2012.

[11] P. Hasle, A. Nielsen, K. Edwards. Application of Lean 
Manufacturing in Hospitals - the Need to Consider Maturity, Complexity, and the Value Concept, Human Factors and Ergonomics in Manufacturing and Service Industries, Vol.26, 430-442, 2016.

[12] A. Eriksson, R. Holden, A. Williamsson, L. Dellve. A Case Study of Three Swedish Hospitals' Strategies for Implementing Lean Production, Nordic Journal of Working Life Studies, Vol.6, 105-131, 2016.

[13] N. Neufield, E. Hoyer, P. Cabahug, M. Gonzálex-Fernández, M. Mehta, N. Walker, R. Mayer. A lean Six Sigma quality improvement project to increase discharge paperwork completeness for admission to a comprehensive integrated inpatient rehabilitation program, American Journal of Medical Quality, Vol.28, 301-307, 2013.

[14] C. Kenney. Transforming health care: Virginia Mason's pursuit of the perfect patient experience, New York, NY, Productivity Press, 2011.

[15] J. Aherne, J. Whelton. Applying lean in healthcare: A collection of international case studies, New York, NY, Productivity Press, 2010.

[16] S. Womack, T. Armstrong, J. Liker. Lean job design and musculoskeletal disorder risk: A two plant comparison, Human Factors and Ergonomics in Manufacturing and Service Industries, Vol.19, 279-293.

[17] J. Liker, D. Meier. The Toyota Way Fieldbook: A Practical
Guide for Implementing Toyota's 4Ps. New York, NY, McGraw-Hill Education, 2006.

[18] W. Preiser. Post-occupancy evaluation: how to make buildings work better, Facilities, Vol.13, No.11, 19-28, 1995.

[19] C. Jimmerson. Value Stream Mapping for Healthcare Made Easy, New York, NY, CRC Press, 2010.

[20] M. Graban, J. Swartz. Healthcare Kaizen - Engaging Front-Line Staff in Sustainable Continuous Improvements, Boca Raton, FL, CRC Press, 2012.

[21] S. Venkateswaran, I. Nahmens, L. Ikuma. Improving healthcare warehouse operations through 5S, IEE Transactions on Healthcare Systems Engineering, Vol.3, No.4, 2013.

[22] D. Mann. Creating a Lean Culture - Tools to Sustain Lean Conversions, New York, NY, CRC Press, 2010.

[23] R. Chalice. Improving Healthcare Using Toyota Lean Production Methods: 46 Steps for Improvement. Milwaukee, WI, ASQ Quality Press, 2007.

[24] Z. Radnor, M. Holweg, J. Waring. Lean in healthcare: The unfilled promise?, Social Science \& Medicine, Vol.74, No.3, 2012.

[25] J. Drew, B. McCallum, S. Roggenhofer. Journey to Lean Making Operational Change Stick, New York, NY, Palgrave MacMillan, 2004. 